\title{
Erratum to: Vision Based Tracking for a Quadrotor Using Vanishing Points
}

\author{
Jose-Ernesto Gomez-Balderas • Pedro Castillo • \\ Jose Alfredo Guerrero • Sergio Salazar • \\ Rogelio Lozano
}

Published online: 11 November 2011

(C) Springer Science+Business Media B.V. 2011

\section{Erratum to: J Intell Robot Syst \\ DOI 10.1007/s10846-011-9579}

Unfortunately, the name of Sergio Salazar, one of the authors of this article, was accidentally omitted during production of this paper. It is now corrected here with his affiliation placed at the bottom of this page.

The online version of the original article can be found at http://dx.doi.org/10.1007/s10846-011-9579-z.

J. E. Gomez-Balderas $(\varangle) \cdot$ P. Castillo ·

J. Guerrero · R. Lozano

Université de Technologie de Compiègne,

Compiègne, France

e-mail: jgomezba@hds.utc.fr

P. Castillo

e-mail: castillo@hds.utc.fr

J. Guerrero

e-mail: jguerrer@hds.utc.fr

R. Lozano

e-mail: rlozano@hds.utc.fr

\section{S. Salazar}

UMI-LAFMIA, CINVESTAV, Av. I.P.N. 2508,

Col. San Pedro Zacatenco C.P. 07360 ,

México, D.F, Mexico

e-mail: ssalazar@ctrl.cinvestav.mx 